\title{
GEOMETRIC EVALUATION OF T AND H-SHAPED CAVITIES INSERTED IN A SOLID WITH HEAT GENERATION APPLYING CONSTRUCTAL DESIGN
}

\begin{abstract}
F. B. Teixeira ${ }^{a}$,
M. S. Pereira ${ }^{a}$, B. C. Feijóa

L. A. O. Rochab,

L. A. Isoldi ${ }^{\mathrm{a}}$, and E. D. Santos ${ }^{\mathrm{a}}$

${ }^{a}$ Universidade Federal do Rio Grande Programa de Pós-Graduação em Engenharia Oceânica (PPGEO)

Av. Itália, km 8, Rio Grande, RS, Brasil fbrancoteixeira@gmail.com

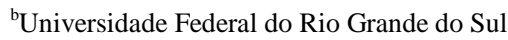

Departamento de Engenharia Mecânica

Rua Sarmento Leite, 425,CEP 90050-170,
\end{abstract}

Porto Alegre, RS, Brasil

Received: May 25, 2017

Revised: June 19, 2017

Accepted: July 17, 2017

Keywords: Constructal design, T-shaped cavity, H-shaped cavity, numerical study, FEM

\section{NOMENCLATURE}

$\mathrm{A}_{0} \quad$ plate area, $\mathrm{m}^{2}$

$\mathrm{A}_{1} \quad$ cavity area, $\mathrm{m}^{2}$

$\mathrm{H}_{0} \quad$ plate height, $\mathrm{m}$

$\mathrm{H}_{1}, \mathrm{H}_{2}, \mathrm{H}_{3}, \mathrm{H}_{4}, \mathrm{H}_{5}, \mathrm{H}_{6}$ cavity dimensions on the vertical direction, $\mathrm{m}$

$\mathrm{H}_{1} / \mathrm{L}_{1}$ aspect ratio of the cavity main section

$\mathrm{H}_{2} / \mathrm{L}_{2}, \mathrm{H}_{3} / \mathrm{L}_{3}$ aspect ratios of the cavity's bifurcations

i vertical step

$\mathrm{k}$ thermal conductivity, $\mathrm{W} /(\mathrm{m} . \mathrm{K})$

$\mathrm{L}_{0} \quad$ plate length, $\mathrm{m}$

$\mathrm{L}_{1}, \mathrm{~L}_{2}, \mathrm{~L}_{3}, \mathrm{~L}_{4}, \mathrm{~L}_{5}$ cavity dimensions on the horizontal direction, $\mathrm{m}$

$q^{\prime \prime \prime}$ rate of energy generation per volume unit, $\mathrm{W} / \mathrm{m}^{3}$

$\mathrm{T}$ temperature, $\mathrm{K}$

$\mathrm{x}, \mathrm{y}$ cartesian coordinates, $\mathrm{m}$

\section{Greek symbols}

$\varphi \quad$ cavity fraction $\left(\mathrm{A}_{1} / \mathrm{A}_{0}\right)$

\section{Superscripts}

f final j current
Subscripts
m once minimized
mm twice minimized
o once optimized
max maximum
oo twice optimized

\section{INTRODUCTION}

With the increased energy requirements of embedded systems and the consequent increase in heat generation, new cooling solutions are needed. Due to this, it is currently attempted to reduce the dimensions of these systems while maintaining the same rate of heat transfer. Problems of diffusion of heat are verified daily, a notorious example is the carcass of the modern cell phones that heats perceptibly with the use of applications and games more and more demanding. In fact, in many cell phones, this process of heat dissipation through the housing is even a design issue to avoid damaging the electronics and the battery. Therefore, the geometries of the components and sinks are of great importance for the proper operation of the equipment, since the 
shape exerts great importance in the processes of heat transfer. Constructal Design is a geometric evaluation method based on the principle of constraints and objectives and a physical principle of maximizing access to flow. This principle is called the Constructal Law defined by Bejan (2000): "For a finite-size system to persist in time (to survive), it must evolve its form and structure to provide better access to the currents flowing through it." Bejan and Lorente (2008), present several applications of the Constructal Law for geometric evaluation in heat transfer problems, Lorenzini and Rocha (2009) studied the geometric optimization of TY-shaped cavities inscribed in a conductive wall and compared with C-shaped cavities. Rocha et. al. (2010) studied the convection cooling in C-shaped cavities. Xie et al. (2010) applied the Constructal Theory in the evaluation of $\mathrm{T}$-shaped cavities inserted in a trapezoidal solid with external adiabatic walls. Hajmohammadi et al. (2013) reanalyzed various cavity shapes (T, Y, T-Y and $\mathrm{H}$ ) and confronted the use of multiple, simpler I-shaped cavities (by simplifying the manufacturing process) by keeping the cavity volume constant.

In this work, the geometry of a cavity inserted in a square solid with uniform heat generation will be numerically studied. The outer surfaces of the solid are thermally insulated and the cavity acts as the sink of the internally generated energy in the solid. The geometry of the cavity will be varied between a $\mathrm{T}$ shape (initial shape) to an irregular H-shape, using the Constructal Design method by Bejan et al. (2012) in order to find the design that presents the best performance. According to Biserni et al. (2007), the optimum configuration in H-shaped cavity has better performance than the optimum T-shaped configuration, but this work intends to analyze the performance gain when maintaining the thickness of the legs of the $\mathrm{T}$ and $\mathrm{H}$--shapes and only varying the lengths in several pre-established widths. There are 50 vertical steps relative to the length of the legs of $\mathrm{T}$ and $\mathrm{H}$-shapes $\left(\mathrm{H}_{1}\right.$ and $\left.\mathrm{H}_{3}\right)$ and 15 horizontal steps relative to the width of the upper stem of the shape $\mathrm{T}$ $\left(\mathrm{L}_{2}\right)$. For the construction of the geometries, the PDE tool of the MATLAB software by Mathworks (2000) was used. The cavity area is maintained at $10 \%$ of the total area of the plate and only its geometry is varied. For the present study, $\mathrm{H}_{1} / \mathrm{L}_{1}$ and $\mathrm{H}_{2} / \mathrm{L}_{2}$ were selected as degrees of freedom. The dimension $\mathrm{H}_{3}$ is plotted against $\mathrm{H}_{1}$, keeping $\mathrm{H}_{2}, \mathrm{~L}_{1}, \mathrm{~L}_{2}, \mathrm{~L}_{3}$ and $\mathrm{L}_{4}$ constant for each horizontal step. With the changed $\mathrm{H}_{2} / \mathrm{L}_{2}$ ratio (horizontal step), a further 50 vertical steps are performed and so on until the 15 horizontal steps are completed. The work will follow equation methods similar to Biserni et. al. (2007) which also numerically analyzes the $\mathrm{H}$ geometry, and will use the same Constructal method applied in Biserni et. al. (2004) and Rocha et al. (2005). The Constructal principle shows that geometry is malleable and is deduced from the principle of global performance maximization also subject to global constraints.

\section{PROBLEM DESCRIPTION}

The system under study consists of a twodimensional, energy diffusion problem in a dimensionless square plate of $1.0 \times 1.0$ side (area $\mathrm{A}_{0}=$ 1.00 ) in which a T-shaped cavity occupying $10 \%$ of $\left(A_{1}=0.10\right)$. In this way, the ratio $A_{1} / A_{0}(\varphi=0.1)$ will be kept fixed. The construction of the initial form did not follow any specific method, since the intention was to maintain $\varphi=0.1$, but some parameters were imposed as $\mathrm{L}_{1}, \mathrm{~L}_{2}, \mathrm{~L}_{3}$ and $\mathrm{H}_{4}\left(\mathrm{H}_{1}+\mathrm{H}_{2}\right)$, being $\mathrm{H}_{3}$ placed as a function of $\mathrm{H}_{1}$ so that the $10 \%$ restriction of the plate area was achieved. In this way, the process of modifying the geometry between the two different shapes ( $\mathrm{T}$ and $\mathrm{H}$ ) was started. Therefore, for the thickness dimensions between the legs of the $\mathrm{H}$ and the lower leg of the T, a ratio of 1:2 was selected. Dimensions $\mathrm{H}_{3}, \mathrm{~L}_{2}$ and $\mathrm{L}_{4}$ (horizontal step) were fixed, and dimension $\mathrm{H}_{1}$ (vertical step) was determined using a spreadsheet tool to obtain $10 \%$ of the board area. In this work, as mentioned before, the initial T-shaped geometry will be varied to an $\mathrm{H}$ shaped for each horizontal step. Fig. 1 (a) and (b) exemplify the initial and final variations, respectively, of the vertical step for a given horizontal step. Fig. 1 (c) and (d) show the initial and final variations respectively of the horizontal step for a given vertical step.

Also in Fig. 1, the boundary conditions imposed on the problem can be seen, where it was considered that the external walls (cross-hatching) are thermally isolated, whereas a minimum prescribed temperature is imposed on the cavity surfaces.

For the problem in question, in each horizontal step $\left(\mathrm{H}_{2} / \mathrm{L}_{2}\right), \mathrm{H}_{1} / \mathrm{L}_{1}$ was varied by keeping the area constant by adjusting the $\mathrm{H}_{3} / \mathrm{L}_{3}$ ratio as a function of $\mathrm{H}_{1}$. The initial dimensions selected are in Tab. 1 and set so that the area is maintained at $10 \%$ of the board area with a minimum precision of $10^{-7}$. This value is selected based on the finding of a technical incapacity of the PDETOOL tool. It was noted during the execution of the work that the software presented errors by varying values in the sixth decimal place as a function of the way in which the tool constructs the geometry and imposes the boundary conditions.

Table 1. Initial plate and cavity dimensions.

\begin{tabular}{|c|c|c|c|}
\hline Variable & Dimension & Variable & Dimension \\
\hline $\mathrm{H}_{0}$ & 1.0000 & $\mathrm{H}_{3}$ & 0.4350 \\
\hline $\mathrm{L}_{0}$ & 1.0000 & $\mathrm{~L}_{3}$ & 0.0300 \\
\hline $\mathrm{H}_{1}$ & 0.8738 & $\mathrm{~L}_{4}$ & 0.3800 \\
\hline $\mathrm{L}_{1}$ & 0.0600 & $\mathrm{H}_{5}$ & 0.1000 \\
\hline $\mathrm{H}_{2}$ & 0.0262 & $\mathrm{~L}_{5}$ & 0.6000 \\
\hline $\mathrm{L}_{2}$ & 0.8200 & $\mathrm{H}_{6}$ & 0.4650 \\
\hline
\end{tabular}




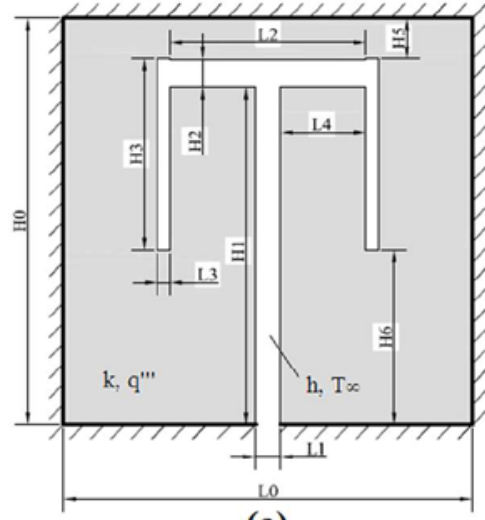

(a)

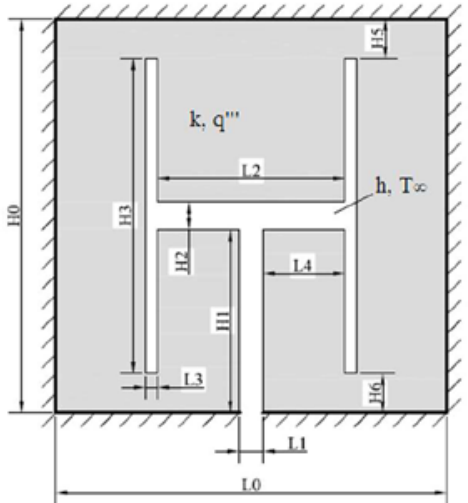

(b)

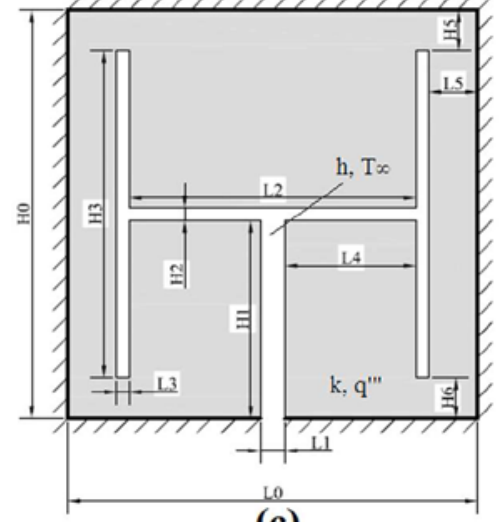

(c)

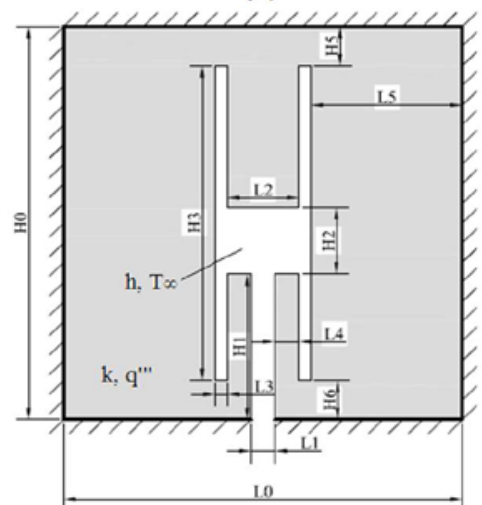

(d)

Figure 1. Description of the problem domain with (a) vertical step 1 and horizontal step 7, (b) vertical step 50 and horizontal step 7, (c) vertical step 50 and horizontal step 1, and (d) vertical step 50 and horizontal step 15.
In addition to these initial dimensions, some final dimensions were imposed as constraints. The final value of $\mathrm{L}_{4}^{\mathrm{f}}$ must be equal to the dimension of $\mathrm{L}_{1}$, that is, $\mathrm{L}_{4}=0.06$ and the final dimension of $\mathrm{H}_{6}$ must equal the size of $\mathrm{H}_{5}, \mathrm{H}_{6}^{\mathrm{f}}=0.1$.

\section{MATHEMATICAL MODELING AND NUMERICAL PROCEDURE}

The equations for the cavity area and the relation as a function of $\mathrm{H}_{1}$ can be seen below.

$$
\begin{gathered}
\mathrm{A}_{1}=H_{1} L_{1}+H_{2} L_{2}+2 H_{3} L_{3} \\
\mathrm{H}_{3}^{\mathrm{i}}=\mathrm{H}_{3}^{0}+\left|\mathrm{H}_{1}^{0}-\mathrm{H}_{1}^{0+\mathrm{i}}\right|
\end{gathered}
$$

where $i$ represents the vertical step.

Starting from the existing boundary conditions and constraints, the energy equation for the present problem in the steady state and two-dimensional domain is given by:

$$
\frac{\partial}{\partial x}\left(k \frac{\partial T}{\partial x}\right)+\frac{\partial}{\partial y}\left(k \frac{\partial T}{\partial y}\right)+q^{\prime \prime \prime}=0
$$

PDETOOL is a tool of commercial software MATLAB and it employs the Finite Element Method (FEM) for mesh creation and problem solving. The mesh generation and refining process is automated by the program, requiring only clicks on the appropriate mesh initialization and refining options. The mesh generated is an unstructured mesh with triangular elements as can be seen in Figs. 2 (a) - (f).

Table 2 shows the mesh independence test for the shape shown in Fig. 2.

Table 2. Analysis of mesh independence.

\begin{tabular}{|c|c|c|}
\hline Elements & $\mathrm{T}_{\max }$ & $\left|\left(\mathrm{T}_{\max }^{J}-\mathrm{T}_{\text {max }}^{\mathrm{J}}\right) / \mathrm{T}_{\max }^{\mathrm{J}}\right|$ \\
\hline 603 & 0.0345540 & $2.70 \times 10^{-2}$ \\
\hline 2,412 & 0.0354871 & $3.95 \times 10^{-3}$ \\
\hline 9,648 & 0.0356274 & $1.51 \times 10^{-3}$ \\
\hline 38,592 & 0.0356811 & $5.81 \times 10^{-4}$ \\
\hline 154,368 & 0.0357018 & $2.26 \times 10^{-4}$ \\
\hline 617,472 & 0.0357099 & - \\
\hline
\end{tabular}

For the work in question, the mesh will be considered independent when $\mid\left(\mathrm{T}_{\text {max }}^{\mathrm{J}}-\mathrm{T}^{\mathrm{J}+1}\right.$ max $) / \mathrm{T}_{\text {max }}^{\mathrm{J}} \mid$ $<5.0 \times 10^{-4}$, so with 4 refinements the most critical shape $(\mathrm{H})$ presented convergence in the required precision.

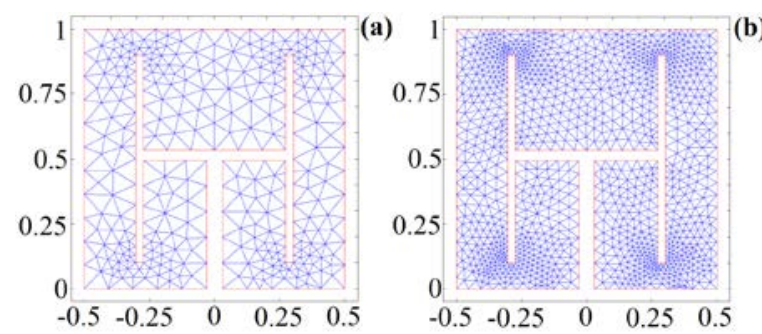



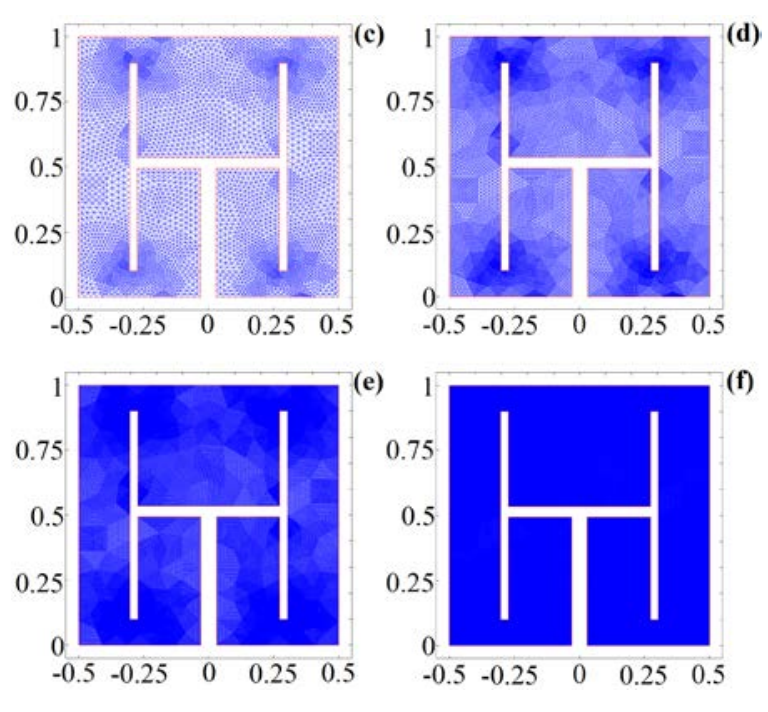

Figure 2. Refining process of the mesh: (a) mesh generated; (b) first refinement; (c) second refinement; (d) third refinement; (e) fourth refinement; (f) fifth refinement.

The optimization process is divided into two steps, as shown in Fig. 3. In the first step, the geometry is optimized through an exhaustive search process by the variation of degree of freedom $\mathrm{H}_{1} / \mathrm{L}_{1}$. The lowest magnitude for the maximum temperature obtained in the domain will be the maximum temperature once minimized $\left(\mathrm{T}_{\max }\right)_{\mathrm{m}}$, while the corresponding optimum geometry will be the once optimized $\mathrm{H}_{1} / \mathrm{L}_{1}$ ratio, $\left(\mathrm{H}_{1} / \mathrm{L}_{1}\right)_{\text {o }}$. In a later step, $\mathrm{H}_{1} / \mathrm{L}_{1}$ is varied for different $\mathrm{H}_{2} / \mathrm{L}_{2}$ values. The lowest value for the maximum temperature obtained will be minimized twice $\left(\mathrm{T}_{\max }\right)_{\mathrm{mm}}$ and the corresponding optimal geometry will be $\left(\mathrm{H}_{1} / \mathrm{L}_{1}\right)_{\text {oo }}$ (twice optimized) and $\left(\mathrm{H}_{2} / \mathrm{L}_{2}\right)_{\mathrm{o}}$ (once optimized).

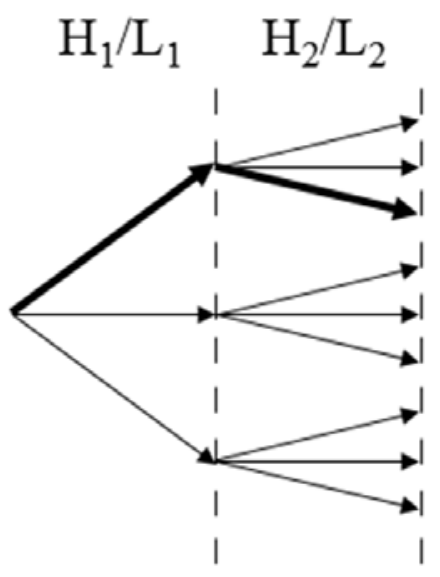

$$
\begin{aligned}
& \left(\mathrm{T}_{\max }\right)_{\mathrm{mm}} \\
& \mathrm{H}_{1} / \mathrm{L}_{1 \circ \circ} \\
& \mathrm{H}_{2} / \mathrm{L}_{2} \circ
\end{aligned}
$$

Figure 3. Diagram illustrating the process of evaluation of the cavity geometry.

\section{RESULTS AND DISCUSSION}

In the simulations, the values of the coefficient of thermal conductivity " $\mathrm{k}$ " and the rate of energy generation per volume unit q"' were kept constant in order to analyze the effects of the geometry variation exclusively. The values will be treated in a dimensionless way since the interest of the study is to analyze the variation presented between the geometries. In this way, the temperature field was determined by the solution of the problem, and the initial value of $\mathrm{H}_{1}$ was then reduced in steps of 0.0073 (vertical step) for each horizontal step whose determined value was 0.02286 . The values for the vertical and horizontal steps were determined in a way that allowed a fixed value of steps (50 vertical and 15 horizontal) respecting the restrictions imposed for the dimensions of $\mathrm{L}_{4}, \mathrm{H}_{5}, \mathrm{~L}_{5}$ and $\mathrm{H}_{6}$. For each step, a new ratio of $\mathrm{H}_{1} / \mathrm{L}_{1}$ and a field of temperatures were obtained. Figure 4 shows the behavior of the maximum temperature taking into account this relation. The values to the right represent the initial form $\mathrm{T}$ and the reduction of this relation indicates the transformation to the form $\mathrm{H}$. The final values to the left for each step, indicates the fully developed form respecting the restriction of $\mathrm{H}_{6}$. In general, it can be seen that the tendency of $\mathrm{T}_{\max }$ to be minimized with the reduction of the $H_{1} / L_{1}$ ratio, that is, with the formation of an $\mathrm{H}$, which confirms the previous studies regarding the best performance of $\mathrm{H}$-shaped geometries in relation to the T-shaped seen in Biserni et. al. (2007). Furthermore, since the $\mathrm{H}_{3} / \mathrm{L}_{3}$ ratio is a function of $\mathrm{H}_{1} / \mathrm{L}_{1}$, since the loss of the central branch area of the cavity due to the decrease in $\mathrm{H}_{1}$ is replaced by the increase of the area of the two branches bifurcated for $\mathrm{H}_{3}$. It can be observed that in the best cases, the best geometry is the one that has intermediate values of $\mathrm{H}_{1} / \mathrm{L}_{1}$, resulting in no gains for the minimization of $\mathrm{T}_{\max }$ by extending the legs of the $\mathrm{H}$ until the end of the domain.

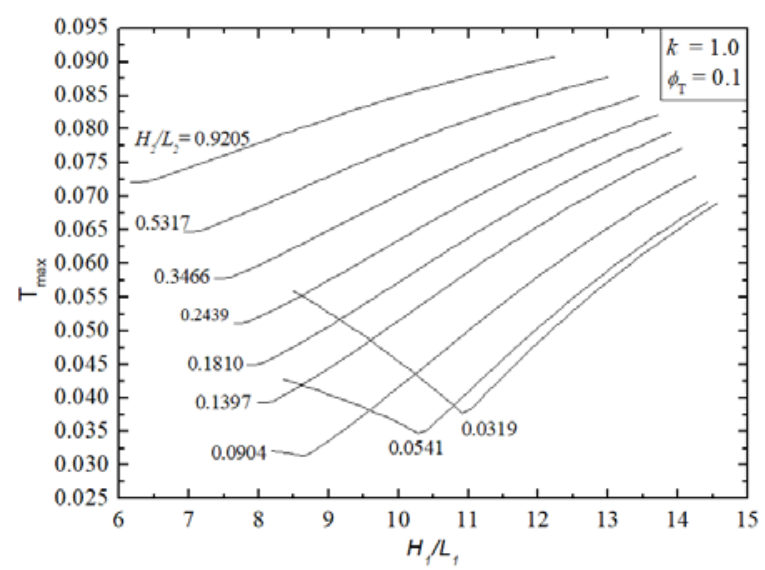

Figure 4. Effect of the $\mathrm{H}_{1} / \mathrm{L}_{1}$ ratio on $\mathrm{T}_{\max }$ for different $\mathrm{H}_{2} / \mathrm{L}_{2}$ ratios.

Analyzing the behavior of $\mathrm{T}_{\max }$ once minimized, $\left(\mathrm{T}_{\max }\right)_{\mathrm{m}}$, as a function of the relation $\mathrm{H}_{2} / \mathrm{L}_{2}$ (Fig. $5 \mathrm{a}$ ), it is possible to find the $\left(\mathrm{T}_{\max }\right)_{\mathrm{mm}}$ (twice minimized) where it was observed a reduction of $54.43 \%$ for the value of the maximum temperature in the plate compared to the form $\mathrm{T}$ initially proposed, and $\mathrm{a}$ 
reduction of $56.93 \%$ when compared to the worst case of the same horizontal step. It is also observed that $\mathrm{H}_{2} / \mathrm{L}_{2}$ ratios higher than 0.1367 present a much lower performance in the minimization of $\mathrm{T}_{\max }$ and are even worse than the initial $\mathrm{T}$ form. Finally, we observed the behavior of $\left(\mathrm{H}_{1} / \mathrm{L}_{1}\right)_{0}$ as a function of $\mathrm{H}_{2} / \mathrm{L}_{2}$ (Fig. 5b).

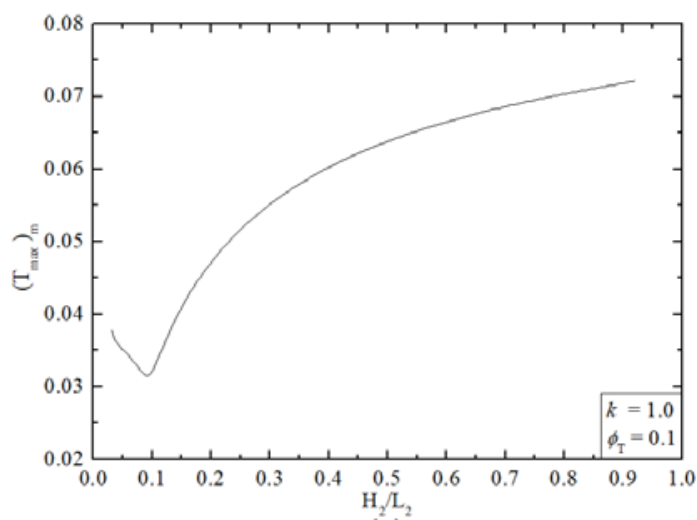

(a)

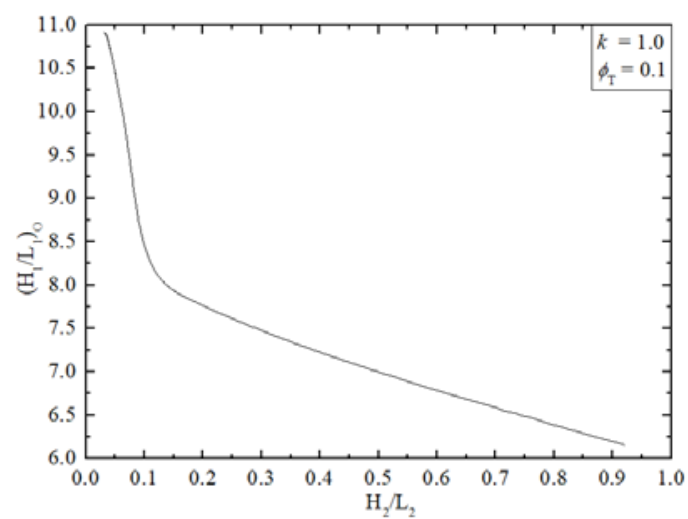

(b)

Figure 5. Effect of $\mathrm{H}_{2} / \mathrm{L}_{2}$ on: (a) $\left(\mathrm{T}_{\max }\right)_{\mathrm{m}}$ (b)

$$
\left(\mathrm{H}_{1} / \mathrm{L}_{1}\right)_{\mathrm{o}} \text {. }
$$

Figures 6 - 8 illustrate the temperature fields for the cases with initial T-shaped configurations (first vertical step) where the ratio $\mathrm{H}_{2} / \mathrm{L}_{2}$ is varied in the following horizontal steps: horizontal step 1, horizontal step 8 (optimal shape for this configuration), horizontal step 50, respectively. Figures 9-11 depict the optimal shapes for the ratios $\mathrm{H}_{2} / \mathrm{L}_{2}$ presented in Figs. 6 to 8, respectively. More precisely, these temperature fields represent the ones obtained with the following parameters: horizontal step 1 and vertical step 30 (Fig. 9), the twice optimized shape with horizontal step 8 and vertical step 46 (Fig. 10) and horizontal step 15 and vertical step 50 (Fig. 11). Table 3 shows the ratios $\mathrm{H}_{1} / \mathrm{L}_{1}$, $\mathrm{H}_{2} / \mathrm{L}_{2}$ and the maximum temperature reached in the domain for the cases presented in Figs. 6 - 11.

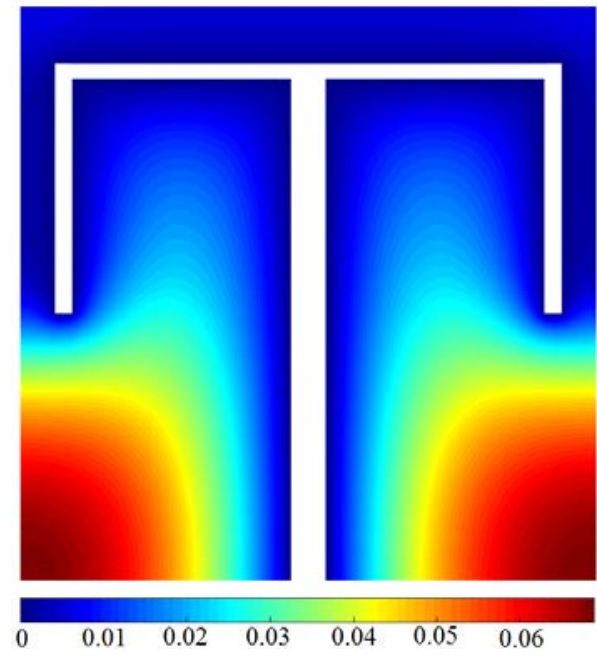

Figure 6. Temperature field obtained for the $\mathrm{T}$ shaped cavity with $\mathrm{H}_{1} / \mathrm{L}_{1}=14.5636$ and $\mathrm{H}_{2} / \mathrm{L}_{2}=$ 0.0319 .

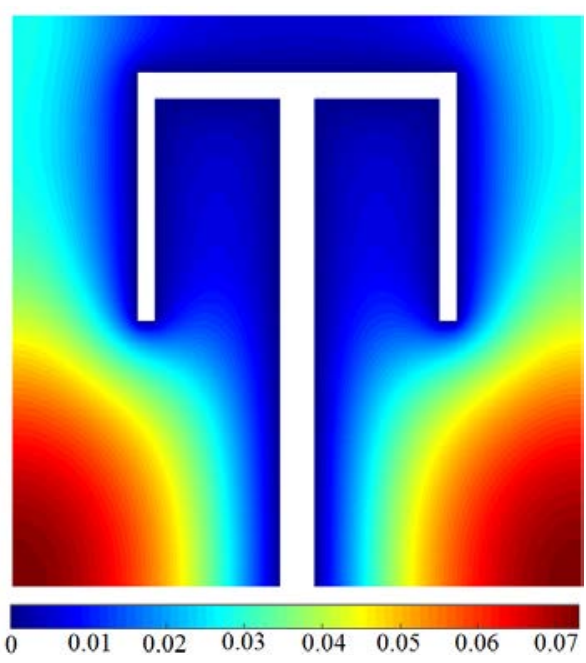

Figure 7. Temperature field obtained for the Tshaped cavity with $\mathrm{H}_{1} / \mathrm{L}_{1}=14.2463$ and $\mathrm{H}_{2} / \mathrm{L}_{2}=$ 0.0904 .

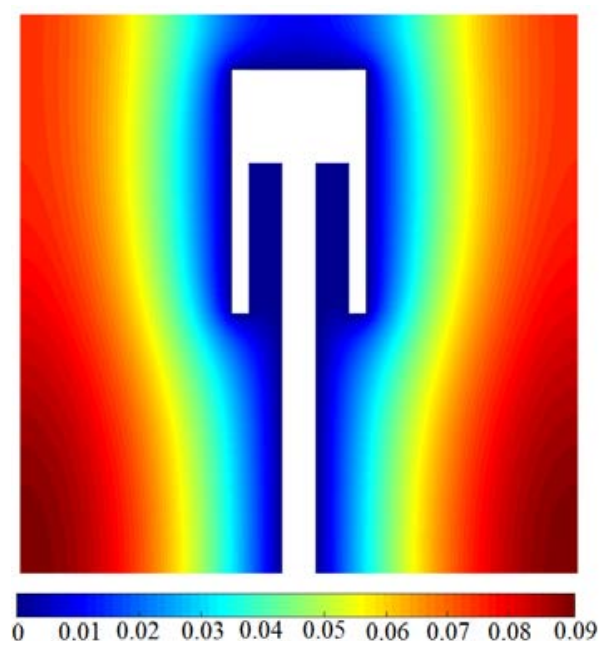

Figure 8. Temperature field obtained for the T- 
shaped cavity with $\mathrm{H}_{1} / \mathrm{L}_{1}=12.2375$ and $\mathrm{H}_{2} / \mathrm{L}_{2}=$ 0.9205 .

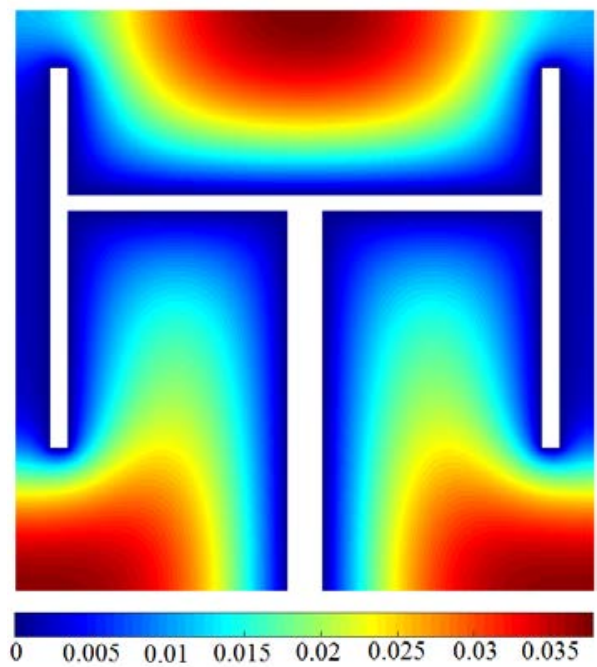

Figure 9. Temperature field obtained for the $\mathrm{H}$ shaped cavity with $\left(\mathrm{H}_{1} / \mathrm{L}_{1}\right)_{0}=10.9136$ and $\mathrm{H}_{2} / \mathrm{L}_{2}=$ 0.0319 .

A decrease in $\mathrm{T}_{\max }$ is observed as $\mathrm{H}_{1} / \mathrm{L}_{1}$ reduces for all cases and the $\mathrm{T}$-shape becomes $\mathrm{H}$-shape. Analyzing Figs. 6 and 9 it is notable the changing of the distribution with two points of maximum for the $\mathrm{T}$-shape and three points of maximum for $\mathrm{H}$-shape. Similarly, comparing Figs. 7 and 10, the initial Tshape also presents two points of maximum, whereas the H-shape shows five maximum points. Therefore, it is noted that the $T_{\max }$ tends to fall with the increase of the maximum points. This can be explained by the principle of optimal distribution of imperfections. The cases shown in Figs. 8 and 11, although they also have a varied form between a $\mathrm{T}$ and $\mathrm{H}$, due to the high ratio of $\mathrm{H}_{2} / \mathrm{L}_{2}$ have somehow only two large zones of maximum temperature.

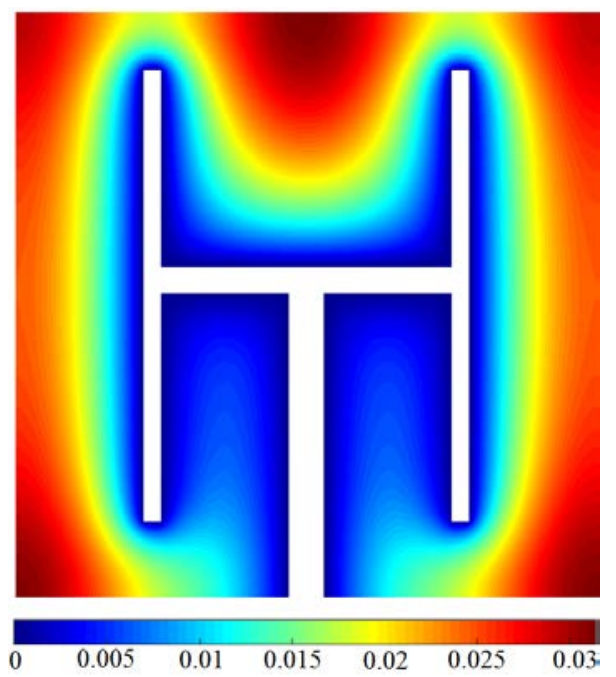

Figure 10. Temperature field obtained for the $\mathrm{H}$ shaped cavity with $\left(\mathrm{H}_{1} / \mathrm{L}_{1}\right)_{\mathrm{oo}}=8.6496$ and $\left(\mathrm{H}_{2} / \mathrm{L}_{2}\right)_{\mathrm{o}}$ $=0.0904$.

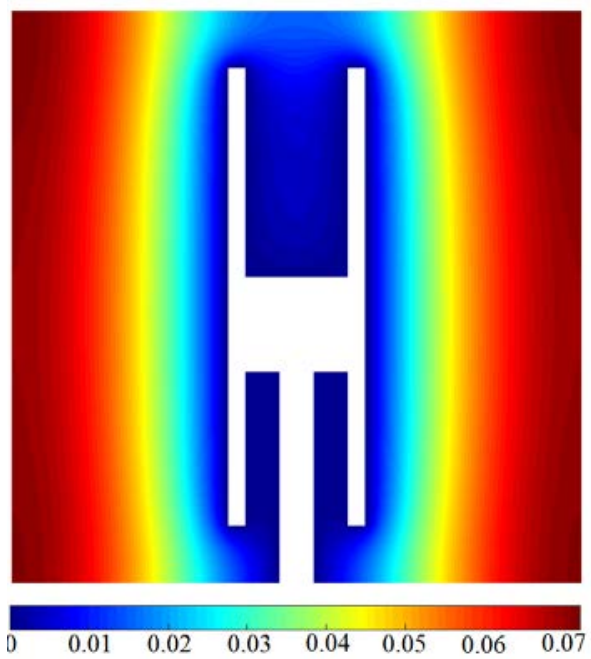

Figure 11. Temperature field obtained for the $\mathrm{H}$ shaped cavity with $\left(\mathrm{H}_{1} / \mathrm{L}_{1}\right)_{0}=6.1542$ and $\mathrm{H}_{2} / \mathrm{L}_{2}=$ 0.9205 .

Table 3 compiles the results obtained for $\mathrm{T}_{\max }$ shown in Figs. $6-11$.

Table 3. Maximum temperatures obtained for the configurations presented in Figs. 6-11.

\begin{tabular}{|c|c|c|c|c|}
\hline $\mathrm{H}_{1} / \mathrm{L}_{1}$ & $\mathrm{H}_{2} / \mathrm{L}_{2}$ & Shape & Figure & $\mathrm{T}_{\max }$ \\
\hline 14.5636 & 0.0319 & $\mathrm{~T}$ & Fig. 6 & 0.068923 \\
\hline 14.2463 & 0.0904 & $\mathrm{~T}$ & Fig. 7 & 0.07299 \\
\hline 12.2375 & 0.9205 & $\mathrm{~T}$ & Fig. 8 & 0.090714 \\
\hline 10.9136 & 0.0319 & $\mathrm{H}$ & Fig. 9 & 0.037755 \\
\hline $\mathbf{8 . 6 4 9 6}$ & $\mathbf{0 . 0 9 0 4}$ & H & Fig. 10 & $\mathbf{0 . 0 3 1 4 1}$ \\
\hline 6.1542 & 0.9205 & H & Fig. 11 & 0.07212 \\
\hline
\end{tabular}

\section{CONCLUSIONS}

A numerical study was carried out to evaluate the geometry of a cavity inserted in a solid with internal energy generation using the Constructal Design method. Geometric optimization is performed using the exhaustive search method. More precisely, an H-shaped cavity has been evaluated which can be simplified to a T-shaped geometry, thus enabling a comparison between the cavities and showing how the geometry can evolve in a flow system. The analyzed system has two restrictions (areas of the solid and cavity) and two degrees of freedom were studied $\left(\mathrm{H}_{1} / \mathrm{L}_{1}\right.$ and $\left.\mathrm{H}_{2} / \mathrm{L}_{2}\right)$. For each new geometry the finite element method was used to solve the energy conservation equation for the heat conduction problem.

For this study, the analysis of only one degree of freedom $\left(\mathrm{H}_{1} / \mathrm{L}_{1}\right)$ reiterates the best performance of $\mathrm{H}$-shaped cavities versus the $\mathrm{T}$-shaped for the minimization of the maximum plate temperature for the same $\varphi$, which is according to Rocha et al. (2005) and Biserni et al. (2007). This occurs even when the $\mathrm{H}$-shape is vertically asymmetrical, that is, it presents 
the upper legs with a size different from the lower ones. The analysis of the second degree of freedom $\left(\mathrm{H}_{2} / \mathrm{L}_{2}\right)$ leads us to conclude that the more symmetrical and centralized $\mathrm{H}$-shape, respecting the previously imposed restrictions, presented the best performance. Using the proposed relationships between the geometric areas and the leg thicknesses of the $\mathrm{T}$ and $\mathrm{H}$ shapes, a minimum $\mathrm{T}_{\max }$ of $54.43 \%$ was found to be lower than the initially established shape, with a reduction of $68.37 \%$ on $\mathrm{H}_{1} / \mathrm{L}_{1}$ and an increase of $64.71 \%$ on $\mathrm{H}_{2} / \mathrm{L}_{2}$. In later works it would be pertinent to study a third and fourth degree of freedom, referring to the thickness of the legs of the $\mathrm{T}$ and $\mathrm{H}\left(\mathrm{L}_{1}\right.$ and $\left.\mathrm{L}_{3}\right)$, arriving at new relations of $\mathrm{H}_{1} / \mathrm{L}_{1}$ and $\mathrm{H}_{3} / \mathrm{L}_{3}$, in order to study more emphatically the questions of vertical and horizontal symmetry of the geometries.

\section{REFERENCES}

Bejan, A., 2000, Shape and Structure, from Engineering to Nature, Cambridge University, Cambridge, UK.

Bejan, A., Lorente, S., and Lee, J., 2008, Unifying Construtal Theory of Tree Roots, Canopies and Forests, Journal of Theorical Biology, Vol. 254, pp. 529-40.

Bejan, A., and Zane, J. P., 2012, Design in Nature: How the Constructal Law Governs Evolution in Biology, Physics, Technology, and Social Organizations, 1st Edition, Anchor Books.

Biserni, C., Rocha, L. A. O., and Bejan, A., 2004, Inverted Fins: Geometric Optimization of the Intrusion into a Conducting Wall, International Journal of Heat and Mass Transfer, Vol. 47, pp. 2577-2586.

Biserni, C., Rocha, L. A. O., Stanescu, G., and Lorenzini, E., 2007, Constructal H-Shaped Cavities According to Bejan's Theory, International Journal of Heat and Mass Transfer, Vol. 50, pp. 2132-2138.

Hajmohammadi, M. R., Poozesh, S., Campo, A., and Nourazar, S. S., 2013, Valuable Reconsideration in the Constructal Design of Cavities, Energy Conversion and Management, Vol. 66, pp. 33-40.

Lorenzini, G., and Rocha, L. A. O., 2009, Geometric Optimization of T-Y-Shaped Cavity According to Constructal Design, International Journal of Heat and Mass Transfer, Vol. 55, pp. 4683-4688.

Mathworks, 2000, MATLAB User's Guide, Version 6.0.088, Release 12, The Mathworks Inc.

Rocha, L. A. O., Lorenzini, E., and Biserni, C., 2005, Geometric Optimization of Shapes on the Basis of Bejan's Constructal Theory, International Communications in Heat and Mass Transfer, Vol. 32, pp. 1281-1288.

Rocha, L. A. O., Lorenzini, E., Biserni, C., and Cho, Y., 2010, Constructal Design of a Cavity Cooled by Convection, International Journal of
Design \& Nature and Ecodynamics, Vol. 5, No. 3, pp. 212-220.

Xie, Z., Chen, L., and Sun, F., 2010, Geometry Optimization of T-Shaped Cavities According to Constructal Theory, Mathematical and Computer Modelling, Vol. 52, pp. 1538-1546. 